\title{
Attenuated Cerulein-Induced Pancreatitis in Nuclear Factor-кB-Deficient Mice
}

\author{
Domenica Altavilla, Ciro Famulari, Maria Passaniti, Mariarosaria Galeano, \\ Antonio Macrì, Paolo Seminara, Letteria Minutoli, Herbert Marini, Margherita Calò, \\ Francesco S. Venuti, Maria Esposito, and Francesco Squadrito
}

Department of Clinical and Experimental Medicine and Pharmacology (DA, MP, PS, LM, HM, ME, FS), Section of Pharmacology, Department of Human Pathology (CF, AM), Section of Emergency Surgery, Department of Surgical Sciences (MG), Section of Plastic Surgery, Department of Neurosciences, Psychiatry, and Anesthesiology (FSV), and Department of Veterinary Pharmacology (MC), University of Messina, Italy

SUMMARY: Nuclear factor (NF)- $\kappa$ B plays a central role in acute pancreatitis. We studied cerulein (CER)-induced pancreatitis in NF- $\kappa$ B knockout (KO) mice. NF- $\kappa$ B KO mice and normal control littermate wild-type (WT) mice were given four hyperstimulating doses of cerulein every hour to elicit secreatagogue-induced pancreatitis. Malonildialdehyde activity, glutathione levels, myeloperoxidase activity, TNF- $\alpha$, and NF- $\kappa \mathrm{B}$ binding activity and its inhibitory protein $\mathrm{I}_{\kappa} \mathrm{B} \alpha$ were studied in the pancreas. Furthermore, we measured plasma lipase and amylase and the histological damage. KO mice had reduced malonildialdehyde levels $(\mathrm{WT}+\mathrm{CER}=4.083 \pm 0.95 \mu \mathrm{mol} / \mathrm{g} ; \mathrm{KO}+\mathrm{CER}=1.513 \pm 0.63 \mu \mathrm{mol} / \mathrm{g})$, decreased myeloperoxidase activity (WT + CER $=19.3 \pm 2.39 \mathrm{mU} / \mathrm{g} ; \mathrm{KO}+\mathrm{CER}=10.21 \pm 2.05 \mathrm{mU} / \mathrm{g}$ ), increased glutathione levels (WT + CER $6.22 \pm 2.46 \mu \mathrm{mol} / \mathrm{g} ; \mathrm{KO}+\mathrm{CER}$ $=15.516 \pm 2.92 \mu \mathrm{mol} / \mathrm{g}$ ), and reduced serum levels of amylase (WT $+\mathrm{CER}=2519 \pm 656.9 \mathrm{U} / \mathrm{L} ; \mathrm{KO}+\mathrm{CER}=916 \pm 280.4$ $\mathrm{U} / \mathrm{L})$ and lipase $(\mathrm{WT}+\mathrm{CER}=1420 \pm 170 \mathrm{U} / \mathrm{L} ; \mathrm{KO}+\mathrm{CER}=861 \pm 172.3 \mathrm{U} / \mathrm{L}) . \mathrm{KO}$ mice showed reduced pancreatic NF- $\kappa \mathrm{B}$ activation, decreased TNF- $\alpha$ tissue content, and reduced histologic alterations. Our data suggest that KO mice have an attenuated cerulein-induced pancreatitis and help to define the possible interaction between NF- $\mathrm{B}$ activation and oxidative stress in this deleterious event. (Lab Invest 2003, 83:1723-1732).

$T$ he severity of pancreatitis results from immunologic events subsequent to acinar cell injury, including the activation and recruitment of inflammatory cells, the local and systemic production and/or release of cytokines, and the final transmigration of those activated inflammatory cells across the endothelial barrier into the involved tissue (Berney et al, 1999). Experimental evidence therefore suggests that up-regulation of inflammatory mediators including cytokines, chemokines, adhesion molecules, and inducible nitric oxide has a central role in this pathologic process (Bhatia et al, 2000; Norman, 1998; Schmid and Adler, 1999).

The cellular mechanism orchestrating these inflammatory mediators involves transcription factors such as nuclear factor (NF) $-\kappa \mathrm{B}$. NF- $\kappa \mathrm{B}$ is an early transcription response complex essential for gene expression of inflammatory molecules (Baeurle and Baichwal, 1995; Ghosh et al, 1998; Wulczyn et al, 1996). NF- $\kappa$ B exists as a complex of homo- or heterodimers com-

\section{DOI: 10.1097/01.LAB.0000101734.82054.BE}

Received July 22, 2003.

Address reprint requests to: Dr. Francesco Squadrito, Department of Clinical and Experimental Medicine and Pharmacology, Section of Pharmacology, Azienda Ospedaliera Universitario "G. Martino", Torre Biologica, 5th Floor, Via Consolare Valeria Gazzi, 98100 Messina, Italy. E-mail: Francesco.Squadrito@unime.it posed of members of the Rel family of proteins (Baeurle and Baichwal, 1995; Ghosh et al, 1998).

In most resting cells, NF- $\kappa \mathrm{B}$ is sequestered within the cytoplasm in an inactive form. After activation, $\mathrm{NF}-\kappa \mathrm{B}$ complexes translocate into the nucleus and activate transcription from target genes. Activation of $\mathrm{NF}-\kappa \mathrm{B}$ has been demonstrated in rat cerulein pancreatitis (Gukovsky et al, 1998; Steinle et al, 1999). Inhibition of NF- $\kappa$ B activation caused significant organ protection and a marked decrease in the expression of several inflammatory cytokines (Steinle et al, 1999).

Oxidative stress has also been implicated in the pathogenesis of acute pancreatitis, and the potential beneficial effects of antioxidants agents have been deeply investigated (Schoenberg et al, 1992; Sweiry and Mann, 1996; Sweiry et al, 1999).

Besides causing direct damage, oxidative stress might also be involved in the triggering of the inflammatory cascade during acute pancreatitis. As a matter of fact, it has been shown that the oxidative state of the cell influences the induction of NF- $\kappa$ B (Schreck et al, 1991). Reactive oxygen intermediates probably induce $\mathrm{I}_{\kappa} \mathrm{B} \alpha$ phosphorilation by influencing the activity of tyrosine kinases (Lee and Burckart, 1998). Furthermore, vitamin E-like antioxidants, which block the lipid peroxidation process, can work as strong inhibitors of $\mathrm{NF}-\kappa \mathrm{B}$ activation (Altavilla et al, 2001; Hattori et al, 1995). 
Mice rendered deficient in p105, the precursor of p50 and one of the components of the multimeric transcription factor NF- $\kappa \mathrm{B}$ (NF- $\kappa \mathrm{B}$ knockout [KO] mice), manifest a number of immunological defects (Cronstein et al, 1999) and represent a useful experimental tool to investigate the role of the transcription factor in experimental-induced pathologies. However, there are no data available in the literature on the effect of cerulein in NF- $\kappa \mathrm{B}$ KO mice. Such an experiment would allow us to determine the exact role of the transcription factor in acute pancreatitis and to investigate whether lipid peroxidation in acute pancreatitis is the cause or consequence of NF- $\kappa \mathrm{B}$ activation.

We therefore investigated whether NF- $\kappa \mathrm{B}$-deficient mice had attenuated pancreatic damage together with a blunted oxidative insult following cerulein administration.

\section{Results}

\section{Lack of p105 mRNA Message and Absence of Both p105 and p50 Proteins in the Pancreas of NF-кB KO Mice}

Figure 1, A and B, shows PCR for p105 message and a Western blot analysis for p105 and p50 in the pancreas of both NF- $\kappa \mathrm{B}$ KO mice and wild-type (WT) animals. These experiments indicate the lack of any
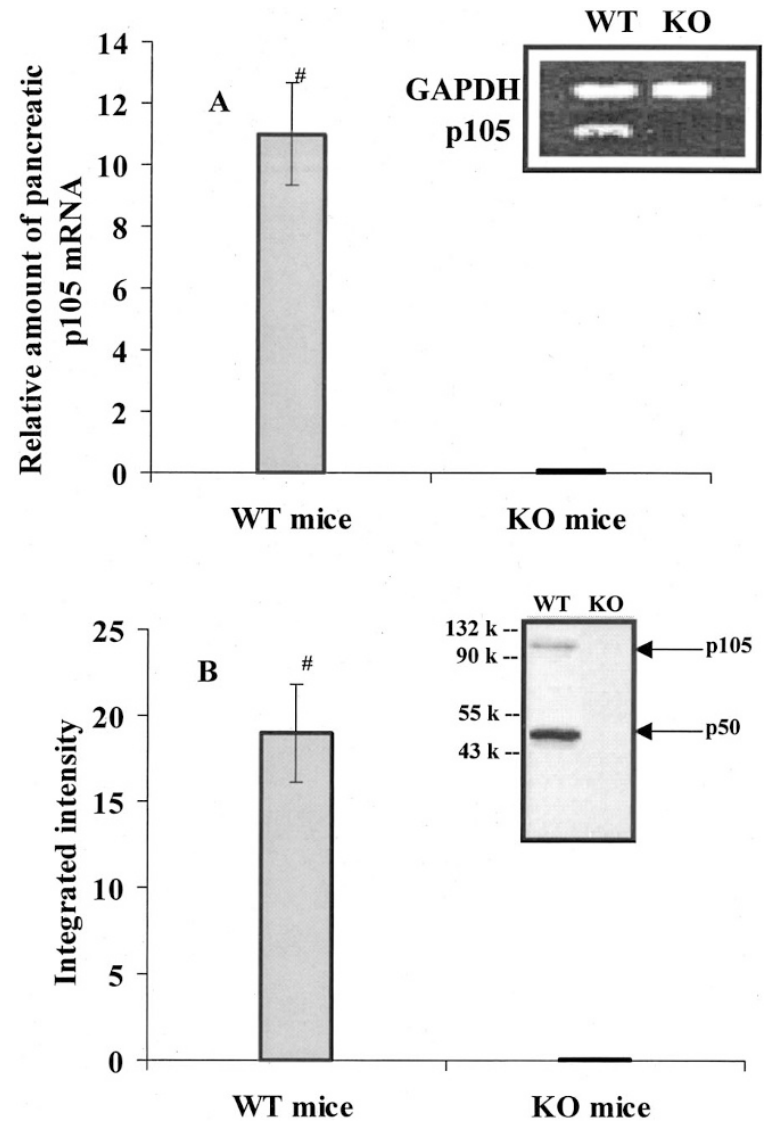

Figure 1.

(A) Pancreatic p105 mRNA expression in wild-type (WT) and nuclear factor (NK)- $\kappa B$ knockout $(K O)$ mice. Bars represent the mean \pm sD of five experiments. (B) Western blot analysis of both p105 and p50 protein levels in the pancreas of WT and NF- $\kappa \mathrm{B}$ KO mice. Bars represent the mean \pm SD of five experiments. GAPDH = glyceraldehyde-3-phosphate dehydrogenase. pancreatic mRNA for p105 as well as the complete absence of both p105 and p50 proteins in the pancreas of KO mice (Fig. 1).

\section{Activation of NF-кB}

$\mathrm{NF}-\kappa \mathrm{B}$ activation in nuclear extracts of the pancreas was determined by electrophoretic mobility shift assay (EMSA). The top of Figure 2 shows a representative EMSA picture indicating NF- $\kappa \mathrm{B}$ activity in several experimental groups. The bottom of the figure shows quantitative data. NF- $\kappa \mathrm{B}-$ binding activity was present at very low levels in $\mathrm{WT}$ and $\mathrm{NF}-\kappa \mathrm{B} \mathrm{KO}$ mice administered with vehicle. Pancreas harvested from cerulein-injected WT mice showed a significant increase in NF- $\kappa$ B binding activity (Fig. 2). KO mice had a markedly decreased NF- $\kappa \mathrm{B}$ binding activity (Fig. 2).

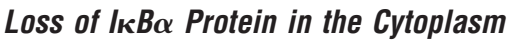

The top of Figure 3 shows representative Western blot analysis indicating $I_{\kappa} \mathrm{B} \alpha$ protein in the cytoplasm of pancreas obtained from several experimental groups. The bottom of the figure indicates quantitative data. $I_{\kappa} \mathrm{B} \alpha$ protein levels were present in the pancreas of WT and NF- $\kappa \mathrm{B}$ KO mice administered with vehicle (Fig. 3). Pancreas obtained from cerulein-injected WT mice showed a marked loss of the protein (Fig. 3). KO mice had a significant expression of the inhibitory protein (Fig. 3).

\section{Pancreatic TNF- $\alpha$ mRNA Expression}

The top of Figure 4 depicts representative gels highlighting mRNA expression for TNF- $\alpha$ in several experimental groups. The bottom of the same figure indicates quantitative data. Control pancreas of both WT and $\mathrm{KO}$ mice showed a low constitutive presence of the message for the inflammatory cytokine (Fig. 4). Induction of acute pancreatitis by cerulein resulted in a strong increase of TNF- $\alpha$ message in WT mice. This message was markedly attenuated in the pancreas obtained from cerulein-injected KO mice.

\section{TNF- $\alpha$ Levels and Leukocyte Accumulation in the Pancreas}

Control pancreas of both WT and KO mice showed a low constitutive presence of the TNF- $\alpha$ protein (Fig. $5 A)$. Administration of cerulein markedly increased the pancreatic content of the inflammatory cytokine in WT mice (Fig. 5A). Pancreas obtained from ceruleininjected $\mathrm{KO}$ mice had a marked reduction of the inflammatory cytokine (Fig. 5A).

Leukocyte accumulation in the pancreas was investigated by the means of myeloperoxidase (MPO) activity. Very low MPO activities were measured in the pancreas of control pancreas of both WT and KO mice (Fig. 5B). By contrast cerulein injection caused a marked leukocyte accumulation in the pancreas of WT mice (Fig. 5B). The administration of cerulein in $\mathrm{KO}$ mice resulted in blunted pancreatic MPO levels (Fig. 5B). 


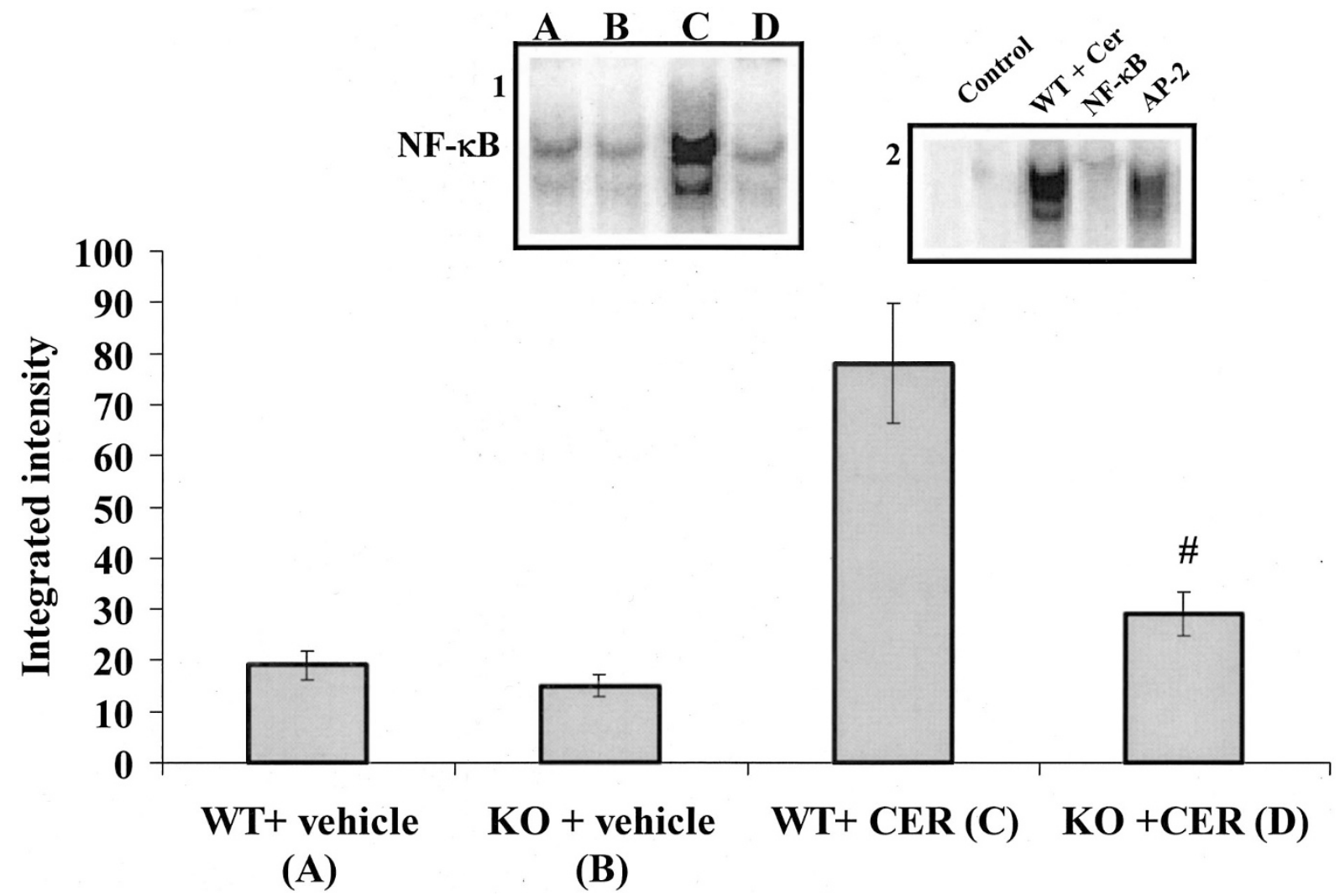

Figure 2.

Electrophoretic mobility shift assay (EMSA) of nuclear factor (NF)- $\kappa$ B-binding activity in the nucleus of pancreas harvested from wild-type (WT) and NF- $\kappa$ B knockout $(K O)$ mice injected with either vehicle or cerulein $(C E R)$. Bars represent the mean $\pm S D$ of seven animals. \#p $<0.01$ vs WT + CER. Panel 1 shows representative autoradiograms highlighting NF- $\kappa$ B binding activity in the several experimental groups. Panel 2 shows EMSA competition experiments. Control: NF- $\kappa B$ without nuclear extract. WT + CER: nuclear extracts from CER-challenged pancreas. NF- $\kappa$ B or AP-2: same extract as WT + CER but including 50-fold molar excess unlabeled NF- $\kappa$ B or AP-2.
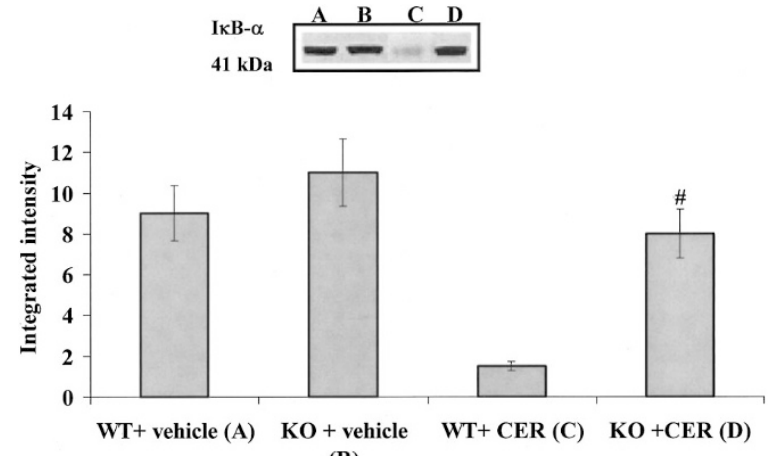

(B)

Figure 3.

Western blot analysis of $I_{\kappa} B \alpha$ protein levels in the cytoplasm of pancreas harvested from wild-type (WT) and nuclear factor (NF)- $\kappa$ B knockout (KO) mice injected with either vehicle or cerulein $(C E R)$. Bars represent the mean \pm SD of seven animals. $\# p<0.001$ vs WT + CER.

\section{Pancreatic Malondialdehyde (MAL) and GSH Determination}

Lipid peroxidation was evaluated by determination of pancreatic MAL 1 hour after the last cerulein injection. Very low MAL levels were measured in tissues obtained from control WT and KO mice given vehicle (Fig. 6A). By contrast cerulein caused a marked increase in pancreatic MAL in WT mice (Fig. 6A). Ad- ministration of cerulein in $\mathrm{KO}$ mice resulted in reduced pancreatic MAL (Fig. 6A).

Glutathione (GSH) levels were similar in control WT and $\mathrm{KO}$ mice given vehicle (Fig. 6B). Cerulein produced a severe depletion of $\mathrm{GSH}$ in the pancreas of WT mice (Fig. 6B). The depletion of pancreatic GSH was markedly reduced in $\mathrm{KO}$ mice (Fig. 6B).

\section{Severity of Cerulein-Induced Pancreatitis}

Several parameters that characterize the severity of secretagogue-induced pancreatitis were measured. Injection of cerulein enhanced serum lipase and amylase activity (Fig. 7, A and B) and also resulted in significant pancreas edema (Fig. 7C) in WT mice. KO mice given cerulein showed a marked reduction in the markers of pancreatitis severity. As matter of fact, KO animals had a blunted increase in serum lipase and amylase activity and reduced pancreas edema (Fig. 7, A to $C)$ following cerulein injection.

\section{Histological Studies}

WT and KO mice treated with vehicle had a normal histology of the pancreas. Lobules and acini of the pancreas were intact; the acinar cells were intact, and the acinar nuclei had a peripheral placement. No 


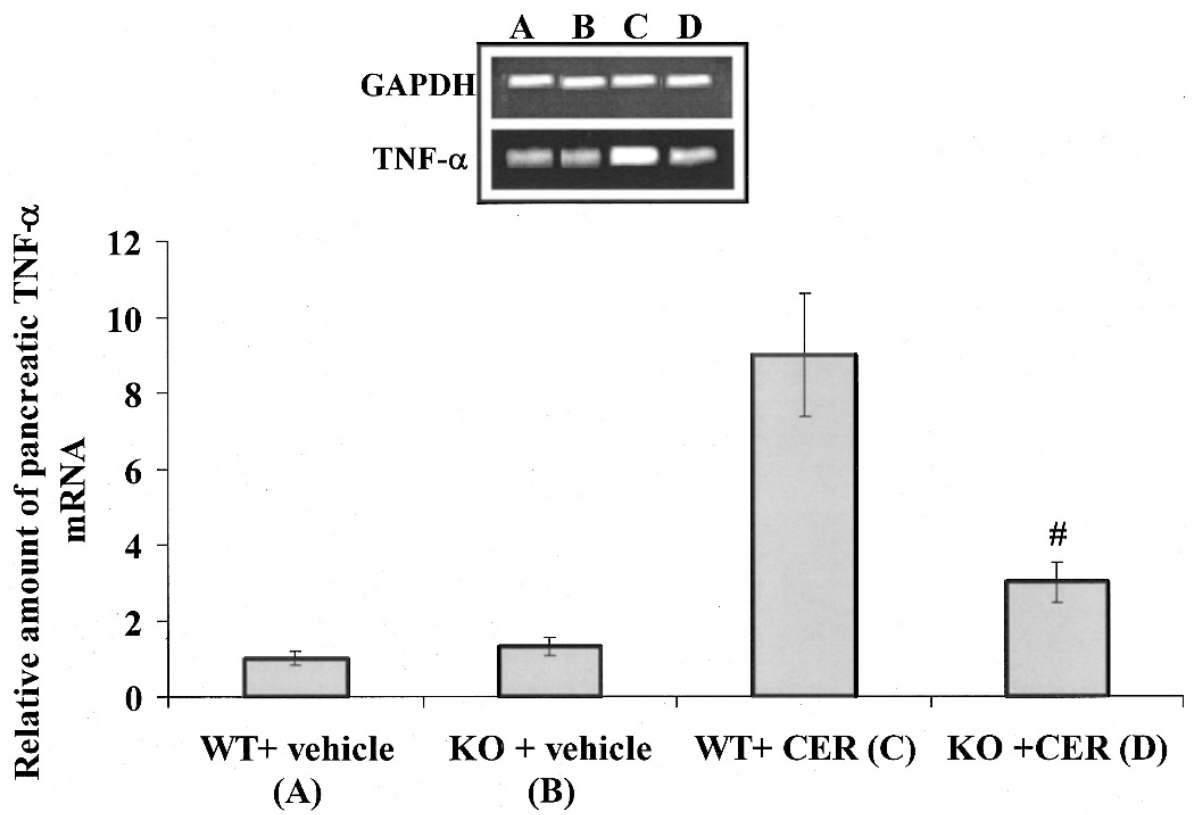

Figure 4.

Pancreatic TNF- $\alpha$ mRNA expression in samples harvested from wild-type (WT) and nuclear factor (NF)- $\kappa$ B knockout $(K O)$ mice injected with either vehicle or cerulein $(C E R)$. Bars represent the mean \pm sD of seven animals. $\# p<0.001$ vs WT + CER. GAPDH = glyceraldehyde-3-phosphate dehydrogenase.
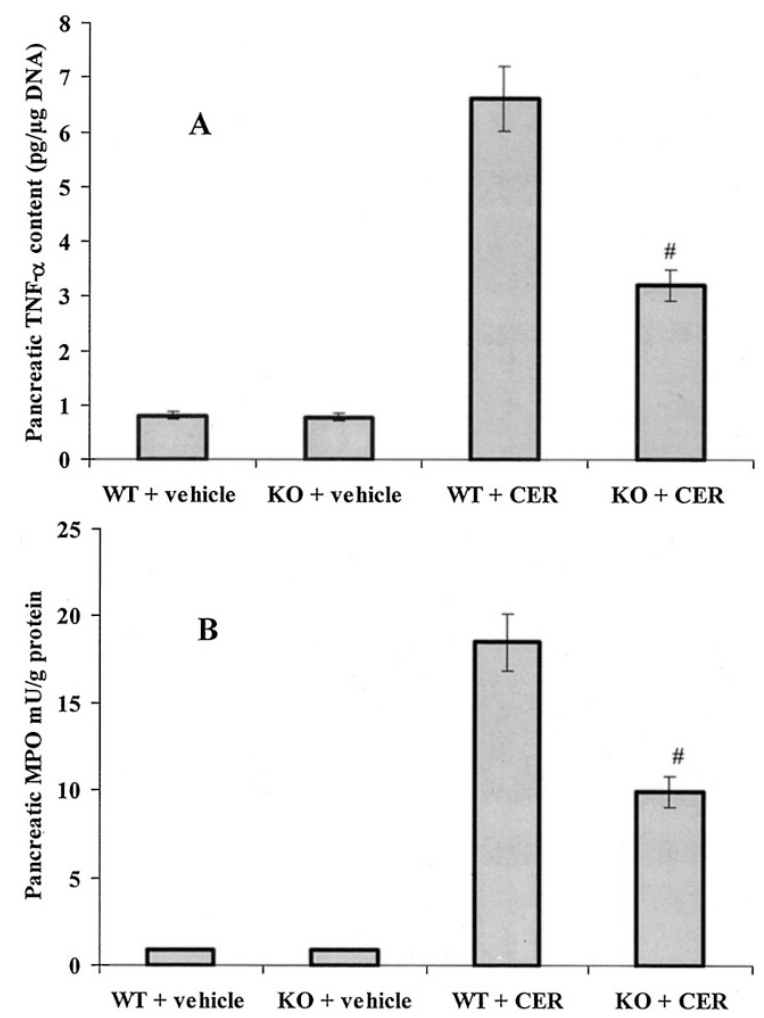

Figure 5.

(A) Pancreatic TNF- $\alpha$ levels in wild-type (WT) and nuclear factor (NF)- $\kappa \mathrm{B}$ knockout $(K O)$ mice injected with either vehicle or cerulein $(C E R)$. Bars represent the mean \pm SD of seven animals. \#p $<0.01$ vs WT + CER. (B) Pancreatic myeloperoxidase (MPO) activity in wild-type (WT) and NF- $\kappa$ B KO mice injected with either vehicle or CER. Bars represent the mean \pm SD of seven animals. $\# p<0.001$ vs WT + CER.

significant structural differences were observed between WT and KO mice following vehicle injection (results not shown). Light microscopy histology showed that cerulein-induced pancreatitis caused interstitial edema, inflammatory cells infiltration, and at higher magnification, presence of cytoplasmatic vacuolization in WT mice (Table 1 and Fig. 8, A and B). KO mice had significantly reduced histological alterations in the pancreas following cerulein administration (Table 1 and Fig. 8, C and D).

\section{Discussion}

An inflammatory cascade has been implicated in the pathogenesis of acute pancreatitis (Ahn et al, 2001; Mikawa et al, 2001). TNF- $\alpha$ is detected in plasma early in the course of acute pancreatitis, and pretreatment of rats with antibodies raised against the inflammatory cytokine reduces elevated serum amylase in acute pancreatitis (Demols et al, 2000). Nevertheless, TNF- $\alpha$ levels in the serum may underestimate the production of the pleiotropic cytokine because of the short serum half-life of TNF- $\alpha$.

In the present study, we therefore investigated the pancreatic content of the inflammatory cytokine as well as its mRNA. The results clearly showed that TNF- $\alpha$ was up-regulated in the pancreas of WT mice following cerulein hyperstimulation as previously shown (De Beaux and Fearon, 1996). The mechanism or mechanisms by which TNF- $\alpha$ causes organ injury and damage has already been pointed out. The inflammatory cytokine might promote organ damage by inducing deleterious leukocyte accumulation within the pancreas, and, therefore, through this mechanism it may cause additional injury and inflammation (Denham et al, 1997). In agreement with this hypothesis, the increased production of TNF- $\alpha$ triggered in our experiment an inflammatory cascade that led to the 

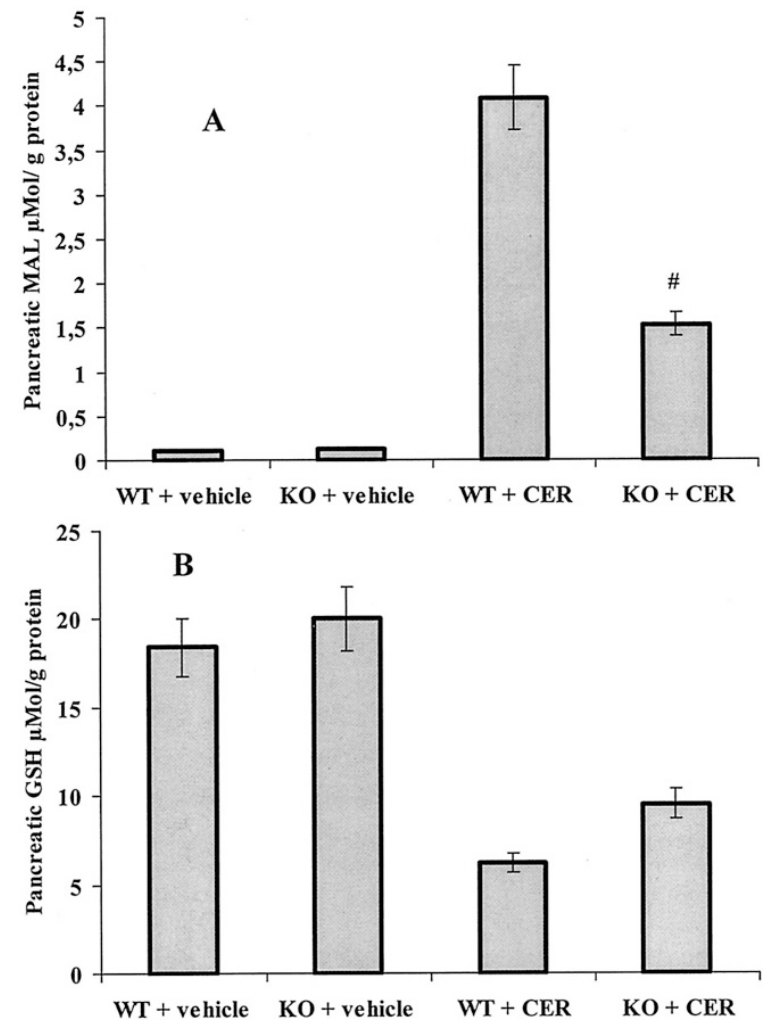

Figure 6.

(A) Pancreatic content of malonildialdehyde (MAL) levels in wild-type (WT) and nuclear factor (NF)- $\kappa$ B knockout $(K O)$ mice injected with either vehicle or cerulein (CER). Bars represent the mean \pm SD of seven animals. $\# p<0.005$ vs WT + CER. (B) Pancreatic content of glutathione (GSH) levels in WT and $\mathrm{NF}-\kappa \mathrm{B} K \mathrm{KO}$ mice injected with either vehicle or CER. Bars represent the mean \pm SD of seven animals. $\# p<0.001$ vs WT + CER.

deleterious tissue leukocyte accumulation and to subsequent organ damage, as indicated by the increase in both amylase and lipase, as well as by marked tissue damage.

A central regulator of cytokine induction is the pleiotropic transcription factor NF- $\kappa$ B. NF- $\kappa \mathrm{B}$ is an early transcription factor that modulates gene expression in various situations that require rapid and sensitive immune and inflammatory response. The prototypic inducible form of $\mathrm{NF}-\kappa \mathrm{B}$ is an heterodimer composed of NF- $\kappa \mathrm{B} 1$ and Rel $\mathrm{A}$, which both belong to the $\mathrm{NF}-\kappa \mathrm{B} / \mathrm{Rel}$ family of proteins. Inactive NF- $\kappa \mathrm{B}$ is present in the cytoplasm complexed with the inhibitory proteins of $I_{\kappa} \mathrm{B}\left(I_{\kappa} \mathrm{B} \alpha, I_{\kappa} \mathrm{B} \beta, \mathrm{Bcl}-3\right.$, and so forth).

$\mathrm{NF}-\kappa \mathrm{B}$ is activated by a number of incoming signals from the cell surface. On activation $I \kappa B$ proteins become hyperphosphorylated and proteolitically degraded. Released from $I_{\kappa} \mathrm{B} \alpha$ inhibition, NF- $\kappa \mathrm{B}$ translocates into the nucleus and binds to the $\kappa \mathrm{B}$ motif of the target gene, in turn causing activation of several factors (cell adhesion molecules and cytokines) involved in the inflammatory response. The selectivity of binding is controlled, at least in part, by distinct protein subunits of NF- $\kappa \mathrm{B}$, such as p65 (RelA), p50, and c-Rel.

It has been demonstrated that cerulein markedly stimulates NF- $\kappa$ B binding activity in experimental pan- creatitis and in isolated pancreatic acini (Grewal et al, 1994; Gukovskaya et al, 1997). Furthermore, treatment with a novel peptide that modifies the NF- $\kappa$ B binding domain attenuates the severity of acute pancreatitis (Ethridge et al, 2002).

Supershift EMSA studies indicated that both p65/ p50 and p/50/p50 dimers, but not c-Rel or p52 complexes, were involved in cerulein-induced pancreatitis and in isolated acinar cells (Gukovskaya et al, 1997). However, a further study indicated that, besides the p50/p65 complex, two other DNA complexes such as p52/65 and RelA/p65 are activated during cerulein pancreatitis (Steinle et al 1999). In agreement with this hypothesis, it has been demonstrated that direct activation of NF- $\kappa \mathrm{B}$ using adeno-viral-mediated transfer of active subunit RelA/p65 causes acute pancreatitis (Chen et al, 2002).

In agreement with previous experimental evidence, our data suggest that cerulein administration in WT mice evoked a sustained activation of the cytoplasmatic transcription factor NF- $\kappa$ B. This event was accompanied by a concomitant depletion of the inhibitory protein $I_{\kappa} \mathrm{B} \alpha$. Thus, NF- $\kappa \mathrm{B}$ activation has a central role in controlling the inflammatory cascade reaction that occurs in experimental pancreatitis induced by cerulein. Indeed, WT mice showed basal detectable levels, albeit low, of NF- $\kappa \mathrm{B}$. A possible explanation could be that the pancreas, to ensure a good enzyme basal secretion, requires a certain NF- $\kappa$ B basal transcriptional activity.

To confirm the role of the transcription factor and more specifically of the p50 dimers in acute pancreatitis, we experimented with mice rendered deficient in p105, the precursor of p50 (Cronstein et al, 1999). Our results indicate that genetically modified mice had attenuated cerulein-induced pancreatic. Indeed $\mathrm{NF}-\kappa \mathrm{B} \mathrm{KO}$ mice showed markedly reduced $\mathrm{NF}-\kappa \mathrm{B}$ activation, decreased TNF- $\alpha$ production, blunted leukocyte accumulation, and improved histology of the pancreas. Therefore, it may be hypothesized that p50 dimers are essential for the development of acute pancreatitis. In addition we have definitely confirmed the role of the transcription factor using, for the first time, KO mice. p105 KO mice still had detectable levels of NF- $\kappa$ B following cerulein injection. It could be hypothesized that our KO mice express some p105 message able to cause a low production of both p105 and p50. PCR and Western blot experiments showed the lack of any pancreatic mRNA for p105, as well as the complete absence of both p105 and p50 proteins in the pancreas, thus ruling out the hypothesis. However, it should be taken into account that two other DNA-binding complexes (p52/p65 and RelA/p65) are activated during cerulein pancreatitis. The latter has a minor role in the development of inflammatory pancreatitis, but in the absence of p50 (as in the case of p105 deficient mice), they might try to substitute the p50/ p65 complex. Indeed their efficacy in mediating the inflammatory response seems to be poor; in fact, cerulein-induced pancreatitis was dramatically blunted in p105 deficient mice. 

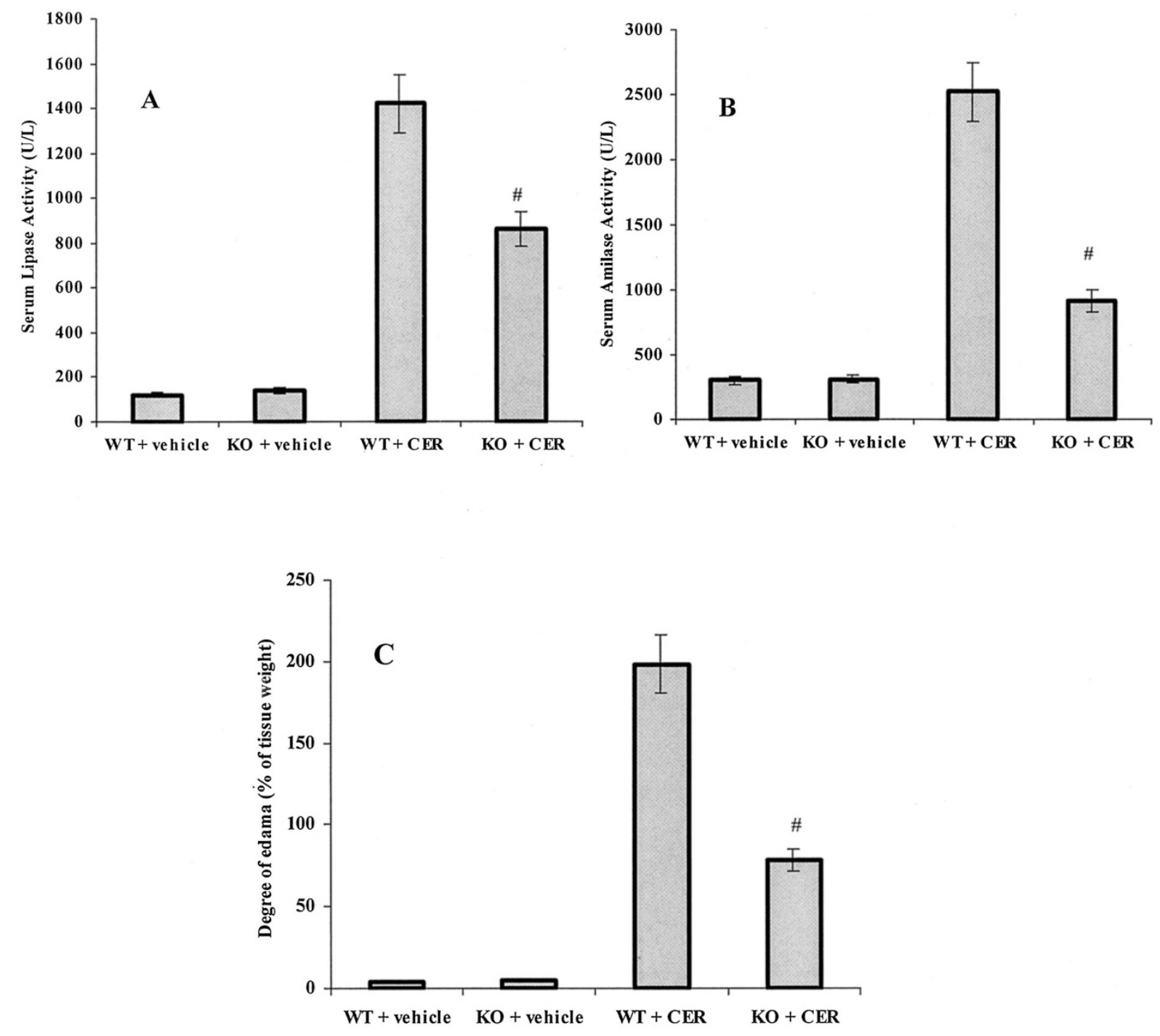

Figure 7.

(A) Serum lipase activity in wild-type (WT) and nuclear factor (NF)- $\kappa B$ knockout $(K O)$ mice injected with either vehicle or cerulein (CER). Bars represent the mean \pm SD of seven animals. $\# p<0.001$ vs WT + CER. (B) Serum amilase activity in WT and NF- $\kappa B$ KO mice injected with either vehicle or CER. Bars represent the mean \pm SD of seven animals. $\# p<0.005$ vs WT + CER. (C) Degree of pancreas edema in WT and NF- $\kappa B$ KO mice injected with either vehicle or CER. Bars represent the mean \pm SD of seven animals. $\# p<0.05$ vs WT + CER.

Apart from phosphorilation, the oxidative state of the cells has been shown to play a key role in NF- $\kappa$ B activation (Frossard et al, 1999, 2001). Several antioxidants, such as $\mathrm{N}$-acetylcysteine, inhibit NF- $\kappa \mathrm{B}$ activation induced by several agents, again reinforcing the notion that reactive oxygen intermediates are deeply involved in this triggering. Moreover, it has been shown that $\mathrm{N}$-acetylcysteine administration in cerulein-induced pancreatitis blocks the activation of the transcription factor and improves the parameters of the disease (Gukovskaya et al, 1997). However, at the present time, there is no conclusive information as to whether lipid peroxidation in acute pancreatitis is a cause or consequence of NF- $\kappa \mathrm{B}$ activation.

Our data clearly indicate that mice rendered deficient in p105, the precursor of p50 and one of the components of the multimeric transcription factor $\mathrm{NF}-\kappa \mathrm{B}$, had a reduced oxidative stress following cer-
Table 1. Histology of Pancreas Harvested from Wild-Type (WT) and Nuclear Factor- $\kappa$ B Knockout Mice (KO) Injected with Either Vehicle or Cerulein

\begin{tabular}{lccc}
\hline Group & $\begin{array}{c}\text { Grade of } \\
\text { interstitial } \\
\text { edema }^{a}\end{array}$ & $\begin{array}{c}\text { Grade of } \\
\text { inflammatory } \\
\text { cell infiltrate }^{a}\end{array}$ & $\begin{array}{c}\text { vacuolization }^{b} \\
\text { (arade of }\end{array}$ \\
\hline $\mathrm{WT}+$ vehicle & 0 & 0 & 0 \\
$\mathrm{KO}+$ vehicle & 0 & 0 & 0 \\
$\mathrm{WT}+$ cerulein & 3 & 3 & 3 \\
KO + cerulein & 1 & 1 & 1 \\
\hline
\end{tabular}

${ }^{a}$ Histologic grading was based on the following scale: 0 , absent; 1 , mild; 2 , moderate; 3 , severe. Statistical analysis was performed using the method of the "mode," which identifies the predominant value in each group $(n=7)$.

${ }^{b}$ Based on the approximate fraction of cells involved: $0,0 \%-25 \% ; 1$, $25 \%-50 \%$; 2, 50\%-75\%; 3, 75\%-100\%. 

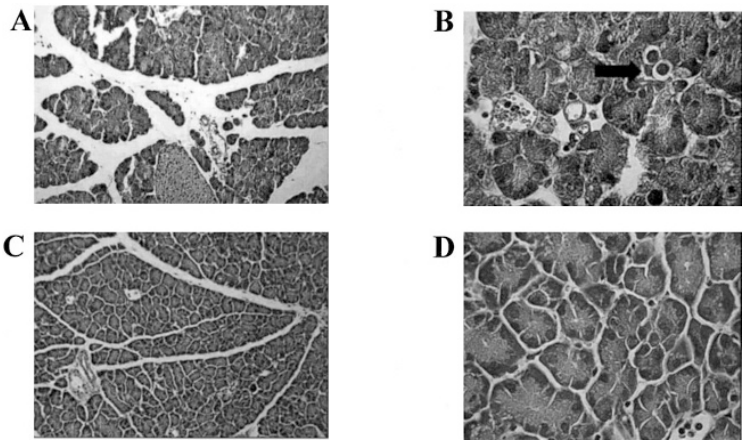

Figure 8.

(A) Representative cerulein (CER)-injected pancreas harvested from a wildtype mouse. Edema: inflammatory cell infiltrates of both interlobular and intralobular interstitium are present (Original magnification, $\times 25)$. (B) Representative CER-injected pancreas harvested from a wild-type mouse. Presence of dark bodies showing apoptotic cells engulfed by acinar cells (arrow) (Original magnification $\times 100$ ). (C) Representative CER-injected pancreas obtained from a nuclear factor $-\kappa B$ knockout mouse. Significant reduction in the edema and in the inflammatory cell infiltrates (Original magnification, $\times 25$ ). (D) Representative CER-injected pancreas obtained from a nuclear factor $-\kappa B$ knockout mouse. The edema is minimal, and the presence of vacuoles is rare. (Original magnification, $\times 100$ ).

ulein administration when compared with WT mice. Indeed NF- $\kappa \mathrm{B} \mathrm{KO}$ animals showed reduced MAL levels and increased GSH content.

Thus, this experimental evidence leads us to hypothesize that the interaction between oxidative stress and $\mathrm{NF}-\kappa \mathrm{B}$ appears to be regulated, at least in cerulein-induced pancreatitis, by a bi-directional mechanism. Lipid peroxidation has a fundamental role in NF- $\kappa \mathrm{B}$ activation, but, as suggested by the present experiment, NF- $\kappa \mathrm{B}$ activation may also amplify the oxidative insult.

In conclusion, our data suggest that NF- $\kappa \mathrm{B}-$ deficient mice show reduced lipid inflammatory response, blunted oxidative stress, and attenuated organ damage following cerulein-induced pancreatitis. This experimental evidence justifies the search for a pharmacologic approach aimed at blocking the inflammatory cascade or alternatively and concomitantly the lipid peroxidation process in acute pancreatitis.

\section{Materials and Methods}

\section{Animals and Treatment}

All procedures complied with the standards for care and use of animal subjects as stated in the Guide for the Care and Use of Laboratory Animals (Institute of Laboratory Animal Resources, National Academy of Sciences, Bethesda, Maryland). Breeding pairs of NF- $\kappa$ B KO mice (p105; b6; 129-Nfkb1 ${ }^{\text {fm1Bal }}$ KO) and normal control littermate WT mice (C57BI/6; 129; WT), both weighing 22 to $30 \mathrm{~g}$, were purchased from The Jackson Laboratory (Bar Harbor, Maine). The animals were bred at Messina University School of Medicine.

Animals were fed a standard diet ad libitum and had free access to tap water. They were maintained on a 12-hour light/dark cycle at $21^{\circ} \mathrm{C}$. To induce acute pancreatitis, animals were administered 4 ip injections $(0.2 \mathrm{ml})$ of a supramaximally stimulating dose of cer- ulein $(50 \mu \mathrm{g} / \mathrm{kg}$ ) every hour to elicit secreatagogueinduced pancreatitis. Control mice (KO and WT) received comparable injections of $0.9 \% \mathrm{NaCl}$. One hour after the final cerulein or saline injection (ie, 1 hour after four injections), animals were killed. Malonildialdehyde activity, GSH levels, MPO activity, TNF- $\alpha$, and $\mathrm{NF}-\kappa \mathrm{B}$ binding activity and its inhibitory protein $\mathrm{I}_{\kappa} \mathrm{B} \alpha$ were studied in the pancreas. The severity of pancreatitis was measured by measuring plasma lipase and amylase, and the degree of pancreas edema and histologic damage was also evaluated.

\section{Lipid Peroxidation Determination}

Determination of pancreas MAL was carried out to estimate the extent of lipid peroxidation in the damaged tissue. Samples of pancreas were frozen at $-70^{\circ} \mathrm{C}$ until the assay. The day of analysis, after the thaw, tissue samples were washed in ice-cold $20 \mathrm{~mm}$ Tris-HCL, $\mathrm{pH} 7.4$, blotted on absorbant paper and weighed. Each sample was then minced in ice-cold 20 $\mathrm{mm}$ Tris-HCL, $\mathrm{pH} 7.4$ and homogenized, in a ratio 1:10 weight to volume (w:v) using a Teflon pestle. After centrifugation at $3000 \times g$ for 10 minutes at $4^{\circ} \mathrm{C}$, the clear homogenate supernatant was used for biochemical assay. The assay was carried out using a colorimetric commercial kit (lipid peroxidation assay kit, cat. no. 437634, Calbiochem-Novabiochem Corporation, La Jolla, California).

Briefly, $0.65 \mathrm{ml}$ of $10.3 \mathrm{~mm} \mathrm{~N}$-methyl-2-phenylindole in acetonitrile was added to $0.2 \mathrm{ml}$ of homogenate supernatant. After vortexing for 3 to 4 seconds and adding $0.15 \mathrm{ml}$ of $\mathrm{HCl} 37 \%$, samples were mixed well and closed with a tight stopper and incubated at $45^{\circ} \mathrm{C}$ for 60 minutes. The samples were then cooled on ice, and the absorbance was measured spectrophotometrically at $586 \mathrm{~nm}$. A calibration curve of an accurately prepared standard MAL solution (from 2 to 128 $\mathrm{nmol} / \mathrm{ml}$ ) was also run for quantification.

\section{Pancreas GSH and TNF- $\alpha$ and Determination of Plasma Amylase and Lipase Activity}

GSH activity was evaluated to estimate endogenous defenses against oxidative stress. Reduced GSH levels in the pancreas were determined as previously described (Farriss and Reed, 1987). Samples were frozen at $-70^{\circ} \mathrm{C}$ until the assay. Briefly, tissue samples were homogenized with an ultra-turrax homogenizer in a solution containing 5\% trichloroacetic acid and $5 \mathrm{~mm}$ ethylenediaminotetracetic acid at $4^{\circ} \mathrm{C}$. Each sample was the centrifuged at $15,000 \times g$ for 10 minutes at $4^{\circ} \mathrm{C}$, and $0.4 \mathrm{ml}$ of homogenate supernatant was added in polyethylene dark tubes containing $1.6 \mathrm{ml}$ Tris-EDTA buffer 0.4 M, pH 8.9. After vortexing, $40 \mu \mathrm{l}$ of dithiobisnitrobenzoic acid $10 \mathrm{~mm}$ was added. The samples were vortexed again, and the absorbance was read after 5 minutes at $412 \mathrm{~nm}$.

The values of unknown samples were drawn from a standard curve plotted by assaying different known concentrations of pancreatic GSH. The amount of pancreatic GSH was expressed as $\mu \mathrm{mol} / \mathrm{g}$ protein. 
TNF- $\alpha$ levels in the pancreas were measured using a commercially available immuno-ELISA kit specific for mouse TNF- $\alpha$.

Plasma amylase and lipase activity was determined using commercially available kits. The values of plasma amylase and lipase activity were expressed as units per liter (U/I).

\section{MPO Activity}

MPO activity was evaluated as an index of neutrophil accumulation in the injured tissue because it correlates closely with the number of neutrophils present in the organ (Mullane et al, 1985). We measured MPO activity in the pancreas 2 hours following the last cerulein injection. Pancreas samples were first homogenated in a solution containing $20 \mathrm{~mm}$ of potassium phosphate to $1: 10(\mathrm{w}: \mathrm{v})$ and then centrifuged for 30 minutes at $20,000 \times g$ at $4^{\circ} \mathrm{C}$. The supernatants of each sample were then discarded, and the pellets were immediately frozen for 12 hours. After the thaw, the resulting pellet was added to a buffer solution consisting of $0.5 \%$ hexadecyltrimethylammonium bromide dissolved in $50 \mathrm{~mm}$ potassium phosphate buffer (pH 6) containing $30 \mathrm{U} / \mathrm{ml}$ aprotinin. Each sample was then sonicated for 1 minute at $4^{\circ} \mathrm{C}$. Then, each sample was centrifuged for 30 minutes at $40,000 \times g$ at $4^{\circ} \mathrm{C}$. An aliquot of the supernatant was allowed to react with a solution of o-dianisidine dihydrochloride $(0.167 \mathrm{mg} / \mathrm{ml})$ and $0.0005 \% \mathrm{H}_{2} \mathrm{O}_{2}$. The rate of change in absorbance was measured spectrophotometrically at $405 \mathrm{~nm}$ (Micro-spectrophotomer model 340 ATTC, SLT Lab Instruments, Austria). MPO activity has been defined as the quantity of enzyme degrading $1 \mu \mathrm{mol}$ of peroxide per minute at $37^{\circ} \mathrm{C}$.

\section{Isolation of Nuclear and Cytoplasmatic Proteins}

Briefly pulverized pancreas samples were homogenized in $0.8 \mathrm{ml}$ ice-cold hypotonic buffer $(10 \mathrm{~mm}$ HEPES pH 7.9, 0.1 mm EDTA, 0.1 mm EGTA, $1 \mathrm{~mm}$ dithiothreitol); protease inhibitors: $0.5 \mathrm{~mm}$ phenyl methylsulfonyl fluoride, aprotinin, pepstatin, and leupeptin [10 $\mu \mathrm{g} / \mathrm{ml}$ each]; and phosphatase inhibitors: $50 \mathrm{~mm}$ NAF, $30 \mathrm{~mm} \beta$-glycerophosphate, $1 \mathrm{~mm}$ $\mathrm{Na}_{3} \mathrm{VO}_{4}$ and $20 \mathrm{~mm} \rho$-nitrophenyl phosphate). The homogenates were centrifuged for 30 seconds at $2000 \mathrm{rpm}$ at $4^{\circ} \mathrm{C}$ to eliminate any unbroken tissues. The supernatants were incubated on ice for 20 minutes, vortexed for 30 seconds after addition of $50 \mu$ l of $10 \%$ Nonidet P-40, and then centrifuged for 1 minute at $4^{\circ} \mathrm{C}$ in an Eppendorf centrifuge. Supernatants containing cytoplasmatic protein were collected and stored at $-80^{\circ} \mathrm{C}$. The pellets, after a single wash with the hypotonic buffer without Nonidet P-40, were suspended in an ice-cold hypertonic salt buffer $(20 \mathrm{~mm}$ HEPES pH 7.9, 0.4 M NaCl, 1 mm EDTA, 1 mm EGTA, $1 \mathrm{~mm}$ dithiothreitol, protease inhibitors, and phosphatase inhibitors), incubated on ice for 30 minutes, mixed frequently, and centrifuged for 15 minutes at $4^{\circ} \mathrm{C}$. The supernatants were collected as nuclear extracts and stored at $-80^{\circ} \mathrm{C}$. The concentration of total proteins in the samples was determined by a commercially available protein assay reagent. To estimate possible contamination of the nuclear extracts with the cytoplasmatic extracts, when preparing the nuclear and cytoplasmatic proteins, lactate dehydrogenase activity was determined by a commercially available kit for the quantitative kinetic determination of lactate dehydrogenase activity (Sigma Chemical, St. Louis, Missouri). Values were expressed as lactate dehydrogenase activity units per milligram of protein. To establish that the nuclear extracts contained mainly nuclear proteins, $40 \mu \mathrm{g}$ of nuclear protein preparations were subjected to Western blot analysis for histone $\mathrm{H} 3$, a nuclear protein, with antihistone $\mathrm{H} 3$ antibody (Upstate Biotechnology, Lake Placid, New York).

\section{EMSA}

$\mathrm{NF}-\kappa \mathrm{B}$ binding activity was performed in a $15-\mu \mathrm{l}$ binding reaction mixture containing $1 \%$ binding buffer (50 $\mu \mathrm{g} / \mathrm{ml}$ of double-stranded poly[dl-dC], $10 \mathrm{~mm}$ Tris $\mathrm{HCl}$ [pH 7.5], $50 \mathrm{~mm} \mathrm{NaCl}, 0.5 \mathrm{~mm}$ EDTA, $0.5 \mathrm{~mm}$ dithiothreitol, $1 \mathrm{mM} \mathrm{MgCl}_{2}$, and $10 \%$ glycerol), $15 \mu \mathrm{g}$ of nuclear proteins, and $35 \mathrm{fmol}(50,000 \mathrm{cpm}$, Cherenkov counting) of double-stranded NF- $\kappa \mathrm{B}$ consensus oligonucleotide (5'-AGT TGA GGG GAC TTT CCC AGG C-8'; Promega, Madison, Wisconsin), which was endlabeled with $\left[\gamma^{32} \mathrm{P}\right]$ ATP $(3000 \mathrm{Ci} / \mathrm{mmol}$ at $10 \mathrm{mCi} / \mathrm{ml}$; Amersham Life Sciences, Arlington Heights, Illinois) using T4 polynucleotide kinase. The binding reaction mixture was incubated at room temperature for 20 minutes and analyzed by electrophoresis on 5\% nondenaturing polyacrylamide gels. After electrophoresis, the gels were dried using a gel drier and exposed to Kodak X-ray films at $-70^{\circ} \mathrm{C}$.

The binding bands were quantified by scanning densitometry of a bio-image analysis system (BioProfil Celbio, Milan, Italy). The results for each time point from each group were expressed as relative integrated intensity compared with the control group pancreas measured in the same batch because the integrated intensity of group samples from different EMSA batches would be affected by the half-life of the isotope, exposure time, and background levels.

EMSA competition experiments were also performed to study the specificity of the oligonucleotide under study. Control experiments using another transcription factor (AP-2) were also done.

\section{Western Blot Analysis of IкBa, p105, and p50 in Cytoplasm}

Cytoplasmatic proteins $(40 \mu \mathrm{g})$ from each sample were mixed with $2 \times$ SDS sample buffer $(62 \mathrm{~mm}$ Tris $[\mathrm{pH}$ 6.8], 10\% glycerol, 2\% SDS, 5\% $\beta$-mercaptoethanol, $0.003 \%$ bromophenol blue), heated at $95^{\circ} \mathrm{C}$ for 5 minutes, and separated by SDS-polyacrylamide gel electrophoresis. After electrophoresis on $12.5 \%$ polyacrylamide gels, the separated proteins were transferred from the gels into Hybond electrochemiluminiscence membranes (Amersham) using a Bio-Rad semidry transfer system 
(Bio-Rad) for 2 hours. The membranes were blocked with 5\% non-fat dry milk in TBS-0.05\% Tween for 1 hour at room temperature, washed three times for 10 minutes each in TBS-0.05\% Tween 20, and incubated with a primary $I_{\kappa} \mathrm{B} \alpha$, p105, or p50 antibody (Santa Cruz Biotechnology) in TBS-0.05\% Tween 20 containing $5 \%$ non-fat dry milk for 1 to 2 hours at room temperature. After being washed three times for 10 minutes each in TBS-0.05\% Tween 20, the membranes were incubated with a second antibody peroxidase-conjugated goat antirabbit IgG (Sigma) for 1 hour at room temperature. After washing, the membranes were analyzed by the enhanced chemiluminescence system according to the manufacturer's protocol (Amersham). The $\mathrm{I}_{\kappa} \mathrm{B} \alpha$ protein signal was quantified by scanning densitometry using a bioimage analysis system (Bio-Profil, Celbio, Milan Italy). The molecular weights markers of $I_{\kappa} \mathrm{B}-\alpha(41 \mathrm{kDA})$, p105 (105 kDA), or p50 (50 kDA) were used as a positive control and to indicate the specificity of our experiment. The results from each experimental group were expressed as relative integrated intensity compared with control normal pancreas measured with the same batch.

\section{RNA Isolation and Reverse Transcriptase PCR}

Total cellular RNA was extracted from a pancreas section. The methods used in the current study have been described elsewhere (Demols et al, 2000). In brief, approximately $100 \mathrm{mg}$ of pancreas was homogenized with $800 \mu l$ RNAZOL STAT (Teltest, Firendswood, Texas) in a microfuge tube, after which $80 \mu$ chloroform was added. After vortexing and centrifugation, the aqueous phase was transferred to a new microfuge tube containing an equal volume of cold isopropanol and the RNA recovered by precipitation by chilling at $-80^{\circ} \mathrm{C}$ for 15 minutes. The pellet was washed with cold ethanol $70 \%$, centrifuged, dried in speed vacuum, centrifuged a second time, and then dissolved in $20 \mu \mathrm{l}$ of buffer. A $2-\mu \mathrm{g}$ portion of total RNA was subjected to first-strand cDNA synthesis in a $20-\mu$ l reaction mixture containing the AMV reverse transcriptase (Superscript II; Gibco BRL), each dNTP, the specific primers, Tris- $\mathrm{HCl}$, and $\mathrm{MgCl}_{2}$.

After dilution of the product with distilled water, $5 \mu \mathrm{l}$ was used for each PCR, which contained the Taq polymerase (Perkin Elmer), the buffer as supplied with the enzyme, each dNTP, and the specific primers designed to cross introns and to avoid confusion between mRNA expression and genomic contamination.

The following oligonucleotide pairs were used $\left(5^{\prime}\right.$ oligo/3'oligo), each sequence as $5^{\prime}$ to $3^{\prime}$ : TNF- $\alpha$ : CACGCTCTTCTGTCTTACTGA/GGACTCCGTGATGTCTAAGTGAPDH: ACCACCATGGAGAAGGTCGG/ CTCAGTGTAGCCCAGGATGGC; p105: TATGCACCGTAACAGCAGGA/GCTATCATAGATGGCGTCTG.; The optimal cycle number for TNF- $\alpha$ and p105 was 25, and we used a PCR-negative and a PCR-positive control without CDNA or with a known cDNA, respectively.
After amplification, the products were subjected to electrophoresis through $2 \%$ agarose (ultrapure, molecular biology grade) and stained with $0.5 \mu \mathrm{g} / \mathrm{ml}$ ethidium bromide in tris-borate ethylene, diaminotetracetic buffer. The captured image was analyzed using image analysis software (Bio-Profil, Celbio, Milano, Italy), subjected to a densitometric analysis, and then printed using a VPN-120 printer.

\section{Histologic Studies and Evaluation of Pancreas Edema}

For light microscopy, a piece from the central body of the pancreas was rapidly removed and fixed in $10 \%$ buffered formalin. Subsequently, it was embedded in paraffin, cut, and stained with hematoxylin and eosin.

Assessment of tissue changes was carried out by an experienced pathologist who was unaware of the treatments. Histologic grading of edema and infiltration of inflammatory cells was based on the following scale: 0 , absent; 1 , mild; 2 , moderate; and 3, severe. Grading of vacuolization was based on the approximate fraction of cells involved: $0,0 \%$ to $25 \% ; 1,25 \%$ to $50 \% ; 2,50 \%$ to $75 \%$; and $3,75 \%$ to $100 \%$.

To measure pancreas edema, a piece from the body of the pancreas was rapidly removed, weighed, and then blotted dry on filter paper. The extent of pancreatic edema was calculated by measuring tissue water content; pancreatic tissue was weighed before and after desiccation at $95^{\circ}$ for 24 hours. The difference between the wet and dry tissue weights was calculated, and the degree of edema was expressed as a percentage of the tissue wet weight.

\section{Drugs}

Cerulein was obtained from Bachem AG Laboratories (Bubendorf, Switzerland).

\section{Statistical Analysis}

Data are expressed as means $\pm S D$ and were analyzed by ANOVA for multiple comparison of results. Duncan's multiple range test was used to compare group means. In all cases, a probability error of $<0.05$ was selected as the criterion for statistical significance. The analysis of the histologic grading was performed by applying the statistical method of the "mode," which identifies the predominant value in each experimental group.

\section{References}

Ahn BO, Kim KH, Lee G, Lee HS, Kim CD, Kim YS, Son MW, Kim WB, Oh TY, and Hyun JH (2001). Effects of taurine on cerulein-induced pancreatitis in the rat. Pharmacology 63: $1-7$.

Altavilla D, Saitta A, Guarini S, Galeano M, Squadrito G, Cucinotta D, Santamaria LB, Mazzeo AT, Campo GM, Ferlito M, Minutoli L, Barzani C, Bertolini A, Caputi AP, and Squadrito $F$ (2001). Oxidative stress causes nuclear factor kappa B activation in acute hypovolemic hemorrhagic shock. Free Rad Biol Med 10:1055-1066. 
Baeurle PA and Baichwal VR (1995). NF-kappa B as a frequent target for immunosuppressive and antiinflammatory molecules. Adv Immunol 65:111-137.

Berney T, Gasche Y, Robert J, Jenny A, Mensi N, Grau G, Vermeulen B, and Morel P (1999). Serum profiles of interleukin-6, interleukin-8, and interleukin-10 in patients with severe and mild acute pancreatitis. Pancreas 18:371-377.

Bhatia M, Brady M, Shokuhi S, Christmas S, Neoptolemos JP, and Slavin J (2000). Inflammatory mediators in acute pancreatitis. J Pathol 117-125.

Chen X, Ji B, Han B, Ernst SA, Simeone D, and Logsdon CD (2002). NF-kappaB activation in pancreas induces pancreatic and systemic inflammatory response. Gastroenterology 122: 448-457.

Cronstein BN, Montesinos MC, and Weissmann G (1999). Salicylates and sulfasalazine, but not glucocorticoids, inhibit leukocyte accumulation by an adenosine-dependent mechanism that is independent of inhibition of prostaglandin synthesis and p105 of $\mathrm{NF}_{\kappa} \mathrm{B}$. Proc Natl Acad Sci USA 96:6377-6381.

De Beaux AC and Fearon KCH (1996). Circulating endotoxin, tumor necrosis factor-alpha, and their natural antagonists in the pathophysiology of acute pancreatitis. Scand J Gastroenterol 219:43-46.

Demols A, Van Laethem JL, Quertinmont E, Legros F, Louis $H$, Le Moine D, and Deviere J (2000). N-acetylcysteine decreases severity of acute pancreatitis in mice. Pancreas 20:161-169.

Denham W, Yang J, Fink G, Denham D, Carter G, Ward K, and Norman J (1997). Gene targeting demonstrates additive detrimental effects of interleukin 1 and tumor necrosis factor during pancreatitis. Gastroenterology 113:1741-1746.

Ethridge RT, Hashimoto K, Chung DH, Ehlers RA, Rajaraman S, and Evers BM (2002). Selective inhibition of NF-KappaB attenuates the severity of cerulein-induced acute pancreatitis. J Am Coll Surg 195:497-505.

Farriss MW and Reed DJ (1987). High-performance liquid chromatography of thiols and disulfides: Dinitrophenol derivatives. Methods Enzymol 143:101-109.

Frossard JL, Pastor CM, and Hadengue A (2001). Effect of hyperthermia on NF- $\kappa$ B binding activity in cerulein-induced acute pancreatitis. Am J Physiol Gastrointest Liver Physiol 280:G1157-G1162.

Frossard JL, Saluja A, Bhagat L, Lee HS, Bhatia M, Hofbauer $B$, and Steer ML (1999). The role of intercellular adhesion molecule 1 and neutrophils in acute pancreatitis and pancreatitis-associated lung injury. Gastroenterology 116: 694-701.

Ghosh S, May MJ, and Kopp EB (1998). NF-kappa B and Rel proteins: Evolutionarily conserved mediators of immune response. Annu Rev Immunol 16:225-260.

Grewal HP, Din AM, Gaber L, Kotb M, and Gaber AO (1994). Amelioration of the physiologic and biochemical changes of acute pancreatitis using an anti TNF- $\alpha$ polyclonal antibody. Am J Surg 167:214-218.
Gukovskaya AS, Gukovsky I, Zaninovic V, Song M, Sandoval D, Gukovsky S, and Pandol SJ (1997). Pancreatic acinar cells produce, release, and respond to tumor necrosis factoralpha. Role in regulating cell death and pancreatitis. J Clin Invest 100:1853-1862.

Gukovsky I, Gukovskaya AS, Blinman TA, Zaninovic V, and Pandol SJ (1998). Early NF- $\kappa$ B activation is associated with hormone-induced pancreatitis. Am J Physiol 275:G1402G1414.

Hattori S, Hattori Y, Banba N, Kasai K, and Shimoda S (1995). Pentamethyl-hydroxychromane, vitamin E derivative, inhibits induction of nitric oxide by bacterial lipopolysaccharide. Biochem Mol Biol Int 35:177-183.

Lee J and Burckart GJ (1998). Nuclear factor kappa B: Important transcription factor and therapeutic target. J Clin Pharmacol 981-993.

Mikawa K, Kodama SI, Nishina K, and Obara H (2001). ONO-1714, a new inducible nitric oxide synthase inhibitor, attenuates diaphragmatic dysfunction associated with cerulein-induced pancreatitis in rats. Crit Care Med 29:12151221.

Mullane KR, Kraemer R, and Smith B (1985). Myeloperoxidase activity as a quantitative assessment of neutrophil infiltration into ischaemic myocardium. J Pharmacol Meth 14:157-167.

Norman J (1998). The role of cytokines in the pathogenesis of acute pancreatitis. Am J Surg 175:76-83.

Schmid RM and Adler G (1999). Cytokines in acute pancreatitis: New pathophysiological concepts evolve. Eur J Gastroenterol Hepatol 125-127.

Schoenberg MH, Buchler M, and Beger HG (1992). The role of oxygen radicals in experimental acute pancreatitis. Free Radic Biol Med 12:515-522.

Schreck R, Rieber P, and Baeuerle P (1991). Reactive oxygen intermediates as apparently widely used messengers in the activation of NF- $\kappa$ B transcription factor and HIV-1. EMBO J 10:2247-2258.

Steinle AU, Weidenbach H, Wagner M, Adler G, and Schmid RM (1999). NF- $\kappa B /$ Rel activation in cerulein pancreatitis. Gastroenterology 116:420-430.

Sweiry JH and Mann GE (1996). Role of oxidative stress in the pathogenesis of acute pancreatitis. Scand J Gastroenterol 219(Suppl):10-15.

Sweiry JH, Shibuya I, Asada N, Niwa K, Doolabh K, Habaray Y, Kanno T, and Mann GE (1999). Acute oxidative stress modulates secretion and repetitive $\mathrm{Ca}^{2+}$ spiking in rat exocrine pancreas. Biochim Biophys Acta 1454:19-30.

Wulczyn FG, Krapmann D, and Scheidereit C (1996). The $\mathrm{NF}-\kappa \mathrm{B} / \mathrm{Rel}$ and $\mathrm{I}-\kappa \mathrm{B}$ gene families: Mediators of immune response and inflammation. J Mol Med 74:749-769. 